\title{
Article \\ Lattice-Match Stabilization and Magnetic Properties of Metastable Epitaxial Permalloy-Disilicide Nanostructures on a Vicinal Si(111) Substrate
}

\author{
Anjan Bhukta ${ }^{1}$, Dror Horvitz ${ }^{2}$, Amit Kohn ${ }^{1}$ and Ilan Goldfarb ${ }^{1, *}$ \\ 1 Department of Materials Science and Engineering, The Iby and Aladar Fleischman Faculty of Engineering, \\ Ramat Aviv, Tel Aviv University, Tel Aviv 6997801, Israel; anjanbhukta@mail.tau.ac.il (A.B.); \\ akohn@tauex.tau.ac.il (A.K.) \\ 2 Thermo Fisher Scientific, Tel Aviv 7019900, Israel; dror.horvitz@thermofisher.com \\ * Correspondence: ilango@tauex.tau.ac.il
}

check for updates

Citation: Bhukta, A.; Horvitz, D.; Kohn, A.; Goldfarb, I. Lattice-Match Stabilization and Magnetic Properties of Metastable Epitaxial

Permalloy-Disilicide Nanostructures on a Vicinal Si(111) Substrate.

Nanomaterials 2021, 11, 1310.

https://doi.org/10.3390/

nano11051310

Academic Editor: Alexander Kromka

Received: 4 May 2021

Accepted: 14 May 2021

Published: 16 May 2021

Publisher's Note: MDPI stays neutral with regard to jurisdictional claims in published maps and institutional affiliations.

Copyright: (C) 2021 by the authors. Licensee MDPI, Basel, Switzerland. This article is an open access article distributed under the terms and conditions of the Creative Commons Attribution (CC BY) license (https:/ / creativecommons.org/licenses/by/ $4.0 /)$.

\begin{abstract}
We report the epitaxial formation of metastable $\gamma-\left(\mathrm{Fe}_{x} \mathrm{Ni}_{1-\mathrm{x}}\right) \mathrm{Si}_{2}$ nanostructure arrays resulting from the reaction of $\mathrm{Ni}_{80} \mathrm{Fe}_{20}$ permalloy with vicinal $\mathrm{Si}(111)$ surface atoms. We then explore the effect of structure and composition on the nanostructure's magnetic properties. The low-temperature annealing $\left(T<600^{\circ} \mathrm{C}\right)$ of a pre-deposited permalloy film led to solid-phase epitaxial nucleation of compact disk-shaped island nanostructures decorating $<110>$ ledges of the stepped surface, with either $(2 \times 2)$ or $(\sqrt{3} \times \sqrt{3})$ R30 ${ }^{\circ}$ reconstructed flat top faces. High resolution scanning transmission electron microscopy analysis demonstrated fully coherent epitaxy of the islands with respect to the substrate, consistent with a well-matched $\mathrm{CaF}_{2}$-prototype structure associated with $\gamma-\mathrm{FeSi}_{2}$, along perfect atomically sharp interfaces. Energy dispersive spectroscopy detected ternary composition of the islands, with $\mathrm{Fe}$ and $\mathrm{Ni}$ atoms confined to the islands, and no trace of segregation. Our magnetometry measurements revealed the superparamagnetic behavior of the silicide islands, with a blocking temperature around $30 \mathrm{~K}$, reflecting the size, shape, and dilute arrangement of the islands in the assembly.
\end{abstract}

Keywords: $\gamma$-(FeNi)Si 2 nanoisland; epitaxial silicide; superparamagnetism; scanning tunneling microscopy

\section{Introduction}

Further technological progress in the field of magnetic data storage and spintronic applications requires the nanoscale miniaturization of magnetic devices with large remanence and energy production [1,2]. This demand has led researchers to combine magnetically hard and soft phases in bi-component type nanomagnets, to facilitate exchange coupling, in the form of core-shell [3,4], bilayer [5-7] and nanocomposite [8] structures. In the absence of exchange coupling in single component nanomagnets, remanent magnetic moment, coercive field, and the shape of the magnetization reversal loop, reflect a single magnetically hard or soft phase.

Although many materials in their bulk form exhibit non-ferromagnetic behavior, noticeable ferromagnetic (FM) properties can be observed in nanometric size crystals, where the appearance of uncompensated magnetic moments is attributed to defects, including nanostructure (NS) boundaries [9-11]. Specifically in fluorite, R- and F-center defects and their immediate surroundings have been theoretically predicted to produce uncompensated spin moments [12]. Geometric and magnetic anisotropy energy (MAE) of such nanoparticles scales with its size, and aligns its individual magnetic moments into a superspin along a particular direction. When nanoparticles are reduced below single domain size, but above the blocking temperature, the superspin flips back and forth on a time scale shorter than the measurement time, exhibiting zero net magnetic moment, namely 
superparamagnetism (SPM). SPM refers to dilute, noninteracting assemblies of nanoparticles smaller than a single domain size. In densely packed arrays, interparticle interaction via dipolar fields may take place, leading to superspin glass (SSG) or superferromagnetic (SFM) state, [13-15]. These three phenomena of "Supermagnetism" (SPM, SSG and SFM), were previously reported by us to take place in epitaxially self-assembled silicide NSs of transition and rare-earth metals, of nonferromagnetic bulk phase origins [16-21]. Often, at least one-dimensional (1D) in-plane ordering of self-assembled silicide phase NSs can be achieved by their decoration of the periodic vicinal Si(hkl) surface step bunches [22,23], as shown in Figure 1 for $5^{\circ}$-miscut $\mathrm{Si}(111)$ in this work.

While defect-induced supermagnetism can be considered "extrinsic", composition, crystal structure, and the resulting electronic structure of binary (or higher) compounds may still have a sizeable "intrinsic" effect on the overall magnetic properties of compound NSs [21]. Metal silicides usually exhibit a sequence of equilibrium phases and epitaxiallystabilized metastable structures. Depending on deposition method, coverage and heat treatment for $\mathrm{Fe}-\mathrm{Si}$ reaction, multiple silicide phases and their metastable variants viz. $\alpha, \beta, \gamma, s$, have been reported, with miscellaneous structural and physical properties [21]. $\alpha$-phase crystallizes in a tetragonal structure and is metallic, whereas the $\beta$-phase has an orthorhombic crystal structure and is semiconducting with a direct $0.87 \mathrm{eV}$ band gap, suitable for application in optical fiber communication, thermoelectricity and optoelectronics. The other two often reported structures, i.e., $\gamma$ and $s$, are metastable, with metallic $\mathrm{CaF}_{2}$ and $\mathrm{CsCl}$ crystal structures, respectively [24-26]. In particular, the $\gamma$ structure is predicted to be ferromagnetic, based on band-structure calculations [27]. Metastable $\gamma$ becomes stabilized by favorable lattice match conditions in epitaxial nanoislands on Si substrates, and its magnetic properties have been occasionally explored by analyzing in-plane magnetization reversal loops $[17,24,28-30]$. A kinetic phase diagram, made on the basis of the contact reaction of $\mathrm{Fe}$ (with thickness less than $1.5 \mathrm{~nm}$ ) on $\mathrm{Si}(111)$, encompassing the $s \rightarrow \gamma \rightarrow \beta$ phase transformation sequence for iron disilicide, reported the existence of the s-phase in the low temperature regime of $300-400{ }^{\circ} \mathrm{C}$ and $\gamma$-phase in the $470-630{ }^{\circ} \mathrm{C}$ range $[31,32]$. Liang et al. has demonstrated transformation of $s \rightarrow \beta$ nanowires on $\mathrm{Si}(110)$ by annealing at $800{ }^{\circ} \mathrm{C}$ [33]. Geng et al. [34], using a first principle study based on density functional theory, have explored the effects of epitaxial strain, free surface, interface and edges of grown nanoislands on the resulting magnetic properties, and concluded that only the edges constituted a sizable contribution to the magnetism of $\gamma-\mathrm{FeSi}_{2} / \mathrm{Si}(111)$ system. By assigning bulk $\mathrm{CaF}_{2}$ structure to the $\gamma-\mathrm{FeSi}_{2} \mathrm{NSs}$, their research studied the implicitly combined intrinsic (composition and crystal and electronic structure) and extrinsic (island boundaries) factors.

To understand the relative contributions of intrinsic vs. extrinsic properties to the observed magnetic response, we examined the epitaxial growth of the magnetic alloys (rather than pure metals) on various Si substrates. Permalloy (Py) $\mathrm{Ni}_{80} \mathrm{Fe}_{20}$ was chosen, because it is a commercial soft magnetic alloy, whose magnetic properties are widely studied and well known, and hence easy to compare with those of the epitaxial NSs of its silicide derivatives. Recently, we reported solid phase epitaxial growth from $\mathrm{Py} \mathrm{Ni}_{80} \mathrm{Fe}_{20}$ on vicinal $\mathrm{Si}(111)$ substrate after a series of stepwise annealing treatments up to $625{ }^{\circ} \mathrm{C}$. In that process, epitaxial disk-like NSs with $(2 \times 2)$ reconstructed top facets preceded the bar-shaped $\beta$ - $\mathrm{Fe}(\mathrm{Ni}) \mathrm{Si}_{2}$ ones, with transformation temperature around $625^{\circ} \mathrm{C}$. Annealing at this temperature caused vertical compositional inhomogeneity within the $\beta-\mathrm{Fe}(\mathrm{Ni}) \mathrm{Si}_{2}$ NSs, in terms of different Fe/Ni ratio at the NSs top and bottom parts, whose coupling effectively created an "exchange spring magnet" (ESM) phenomenon [35]. The purpose of the present work was to achieve control over the appearance of different silicide phases and their composition. Specifically, our aim was to stabilize the precursor flat-top ternary $\gamma-\left(\mathrm{Fe}_{x} \mathrm{Ni}_{1-\mathrm{x}}\right) \mathrm{Si}_{2}$ disk-like NSs and avoid the compositional top-to-bottom gradient of $\mathrm{Ni}$ and/or its loss altogether. We report here on the successful growth of such $\gamma-\left(\mathrm{Fe}_{\mathrm{x}} \mathrm{Ni}_{1-\mathrm{x}}\right) \mathrm{Si}_{2}$ NS disks with $(2 \times 2)$ and $(\sqrt{3} \times \sqrt{3})$ R30 ${ }^{\circ}$ reconstructed top facets and uniform ternary composition. Though these $\gamma$ nanodisks (NDs) were 1D-self-ordered along the periodic 
ledges of the $5^{\circ}$-miscut vicinal $\mathrm{Si}(111)$ substrate by step-decoration mechanism [22,23], as planned, the inter-disk separation distances along the ledge were too large for meaningful dipolar interactions, which accounts for their SPM with a median blocking temperature at around $30 \mathrm{~K}$.

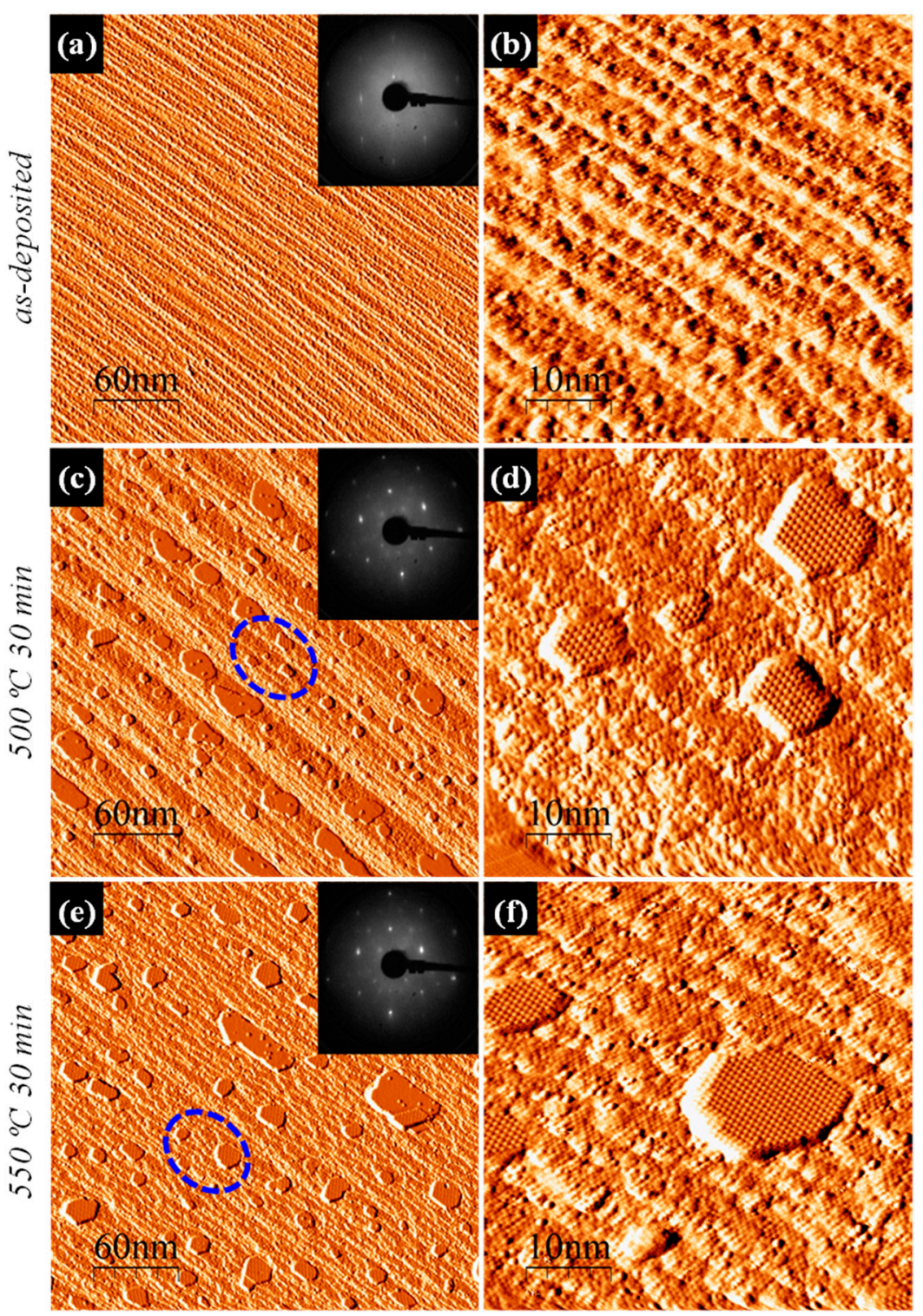

Figure 1. (a,c,e) Low and (b,d,f) high magnification STM topographic derivative images with corresponding LEED patterns in the insets, of various stages of Py SPE growth and anneals on $5^{\circ}$-miscut vicinal $\mathrm{Si}(111)$ substrate: $(\mathbf{a}, \mathbf{b})$ as-deposited, and (c,d) subsequently annealed at $500{ }^{\circ} \mathrm{C}$ for $30 \mathrm{~min}$ and $(\mathbf{e}, \mathbf{f}) 550{ }^{\circ} \mathrm{C}$ for $30 \mathrm{~min}$. Regions encircled in (c,e) are the ones blown-up in (d,f), respectively.

\section{Methods}

In vacuo part of substrate preparation and in situ measurements were conducted in an ultra-high vacuum (UHV, base pressure $2.0 \times 10^{-10}$ mbar) variable temperature scanning tunneling microscopy (STM) by Omicron Nanotechnology $\mathrm{GmbH}$, equipped with reflection high energy electron diffraction (RHEED) and 4-grid low energy electron diffraction (LEED)/Auger spectrometer. $10 \mathrm{~mm} \times 1 \mathrm{~mm}$ stripes were cut from $5^{\circ}$-miscut $\mathrm{Si}(111)$ wafer and ex vacuo chemically degreased prior to introduction into the UHV, where after thorough degassing at $\sim 550{ }^{\circ} \mathrm{C}$ for $12-15 \mathrm{~h}$, the sample was repeatedly flashed at 
1150-1200 ${ }^{\circ} \mathrm{C}$ to remove the native silicon oxide layer. Consequently, the sample was slowly cooled down to room temperature $(\mathrm{RT})$ to obtain well-ordered $(7 \times 7)$ reconstructed terraces separated by periodically bunched steps, evident from electron diffraction and STM measurements. Thin Py film was e-beam evaporated from a high-purity commercial $\mathrm{Ni}_{80} \mathrm{Fe}_{20}$ Py wire onto a flashed stepped Si(111) surface inside the STM stage. A separate sample with an as-deposited Py film was prepared to be used as a reference standard for ex situ chemical and magnetic analyses, with this thin film standard itself calibrated using a bulk piece of the original Py evaporant rod as an absolute standard. Using this rigorous double-standard routine, our X-ray photoelectron spectroscopy (XPS) analysis quantitatively confirmed preservation of the $\mathrm{Ni}_{80} \mathrm{Fe}_{20}$ stoichiometry in this reference film. For LEED study, electron beam energy in the $72-120 \mathrm{eV}$ range was employed. STM images were acquired using the $0.1 \mathrm{nA}<I<1.0 \mathrm{nA}$ and $-3.25 \mathrm{~V}<V<3.0 \mathrm{~V}$ tunneling current and bias, respectively, in a constant-current mode. STM images were processed using WSxM freeware and commercially available SPIP software from Image Metrology.

Ex situ XPS analyses were conducted in a 5600 multi technique ESCA/Auger (PHI, USA) at a base pressure $2.5 \times 10^{-10} \mathrm{mbar}$, incident monochromatic $X$-ray source (using $\mathrm{Al} \mathrm{K} \alpha$ with energy $1486.6 \mathrm{eV}$ ) at a grazing $25^{\circ}$ incidence angle, and spherical capacitor analyzer with slit aperture of $0.8 \mathrm{~mm}$ for analysis of the emitted photoelectrons. Helios G4 UC Dual Focus Ion Beam system from Thermo Fisher has been employed for secondary electron (SE) imaging with $2 \mathrm{keV}$ electron beam and preparation of lamella for transmission electron microscopy (TEM) investigations. A Thermo Fisher Themis Z G3 TEM with a probe corrector for $300 \mathrm{keV}$ electrons was employed for high-angle annular dark-field (HAADF) scanning TEM imaging and multiple ('Super- $X$ ') Silicon Drift Detectors for energy dispersive X-ray spectroscopy (EDS). Macro-magnetic properties were characterized using a superconducting quantum interference device (SQUID) magnetometer (MPMS-3 LOTQuantum Design). The samples were measured using the vibrating sample magnetometry mode with peak amplitude of $4 \mathrm{~mm}$ and averaging time of $5 \mathrm{~s}$. The data was corrected for remnant fields in a 7T-magnet and diamagnetic contribution of the Si substrate.

\section{Results and Discussion}

\subsection{Morphological Evolution upon Annealing}

The morphological evolution of the as-deposited Py on the vicinal Si(111) substrate is evident through a series of topographic STM images and LEED patterns in Figure 1. The asdeposited Py film practically buried the substrate surface underneath, to the extent that the traces of the underlying $\mathrm{Si}(111)-(7 \times 7)$ reconstructed terraces could be barely recognized in STM (Figure $1 \mathrm{a}, \mathrm{b})$, and only characteristically a faint $(1 \times 1)$ pattern on a milky background appeared in LEED (inset of Figure 1a), evidence of the amorphous nature of the coverage on top of now only bulk-terminated substrate. The $(2 \times 2)$-reconstructed NDs began to form in the course of a $500{ }^{\circ} \mathrm{C}$ anneal, mostly by decorating the surface step-bunch ledges (Figure 1c,d). The milky background in the LEED pattern in the inset of Figure 1c was then replaced by mixed $(2 \times 2)+(\sqrt{3} \times \sqrt{3})$ R30 $0^{\circ}$ superlattice diffraction spots (inset of Figure 1c), that became yet clearer and sharper (inset of Figure 1e) after further NDs growth by consumption of dilute Py (Figure 1e,f). We have previously witnessed the formation of a small fraction of $(\sqrt{3} \times \sqrt{3})$ R30 $0^{\circ}$-reconstructed islands within the majority assembly of the $(2 \times 2)$-reconstructed ones, as a reaction product of pure Fe with $\mathrm{Si}(111)$ [17].

\subsection{XPS Study of the Nanodisk Bonding Chemistry}

Figure $2 \mathrm{a}, \mathrm{b}$ represent the core level high resolution $2 \mathrm{p}_{3 / 2}$ XPS peak of Fe and Ni, respectively (shift corrected with respect to adventitious $\mathrm{C} 1 \mathrm{~s}$ spectral position at $285 \mathrm{eV}$ ). Experimental data was analyzed using the Casa XPS software package [36] after background subtraction using Shirley's method [37]. The relative quantification of several binding states of $\mathrm{Fe} 2 \mathrm{p}_{3 / 2}$ and $\mathrm{Ni} 2 \mathrm{p}_{3 / 2}$, based on the integrated intensity of the corresponding spectral line has been detailed in Table 1. Using mixed Gaussian-Lorentzian, i.e., $\mathrm{GL}(\mathrm{m})$ (where $\mathrm{m}=0$ is a pure Gaussian and $\mathrm{m}=100$ is a pure Lorentzian) line shape 
modified by an asymmetric form, major peak of Fe $2 \mathrm{p}_{3 / 2}$ has been obtained at $707.08 \mathrm{eV}$. In our recent study, we reported the growth of $\gamma \mathrm{FeSi}_{2}$ phase on a $(7 \times 7)$ reconstructed $\mathrm{Si}(111)$ substrate with superlattice reconstruction $(2 \times 2)$ and $(\sqrt{3} \times \sqrt{3})$ R30 that corresponded to $\mathrm{Fe} 2 \mathrm{p}_{3 / 2}$ binding energy $707.2 \mathrm{eV}[17,38]$. The similarity of this line energy and shape pointed to the $\mathrm{CaF}_{2}$-based $\gamma$-phase nature of the present NDs, as well. Alongside, the minor peak at $708.59 \mathrm{eV}$ fitted by line shape GL(0) matched well with $\mathrm{FeO}$ which was formed due to air exposure of our sample prior to XPS measurements $[39,40]$. In the case of $\mathrm{Ni} 2 \mathrm{p}_{3 / 2}$, fitting by GL(m) modified by exponential blend indicated only a peak at $853.61 \mathrm{eV}$. It is broadly accepted that the binding $2 \mathrm{p}_{3 / 2}$ energy of metallic $\mathrm{Ni}^{0}$ is $852.6 \mathrm{eV}$, with two main satellites located $3.8 \mathrm{eV}$ and $6 \mathrm{eV}$ above that [41-43]. However the $2 \mathrm{p}_{3 / 2}$ binding energy can rise above $853 \mathrm{eV}$ in permalloys and other binary and ternary alloys and compounds $[42,44,45]$, and in particular values close to those observed here of $853.61 \mathrm{eV}$, reflect the effect of the Si environment [46]. No significant presence of higher oxidation states of $\mathrm{Ni}^{2+}$ and $\mathrm{Ni}^{3+}$ oxides and hydroxides, situated at binding energies of $854 \mathrm{eV}$ and above [47], could be detected in the $\mathrm{Ni} 2 \mathrm{p}_{3 / 2}$ line shown in Figure $2 \mathrm{~b}$.

Table 1. Fitting parameters to high-resolution core level XPS spectra of Fe $2 p_{3 / 2}$ and Ni $2 p_{3 / 2}$ peaks (from Figure 2).

\begin{tabular}{ccccc}
\hline Phase & Binding Energy (eV) & FWHM (eV) & Line Shape & Concentration (\%) \\
\hline \multirow{2}{*}{$\mathrm{-Fe}(\mathrm{Ni}) \mathrm{Si}_{2}$} & 707.08 & 0.92 & $\mathrm{~A}(0.35,0.36,0)$ & 98.88 \\
$\mathrm{FeO}$ & 708.59 & 0.50 & $\mathrm{GL}(53.3333)$ & 1.12 \\
$\mathrm{Ni}(\mathrm{Fe}, \mathrm{Si})$ & 853.61 & 1.22 & $\mathrm{GL}(67.6667)$ & 100 \\
\hline
\end{tabular}
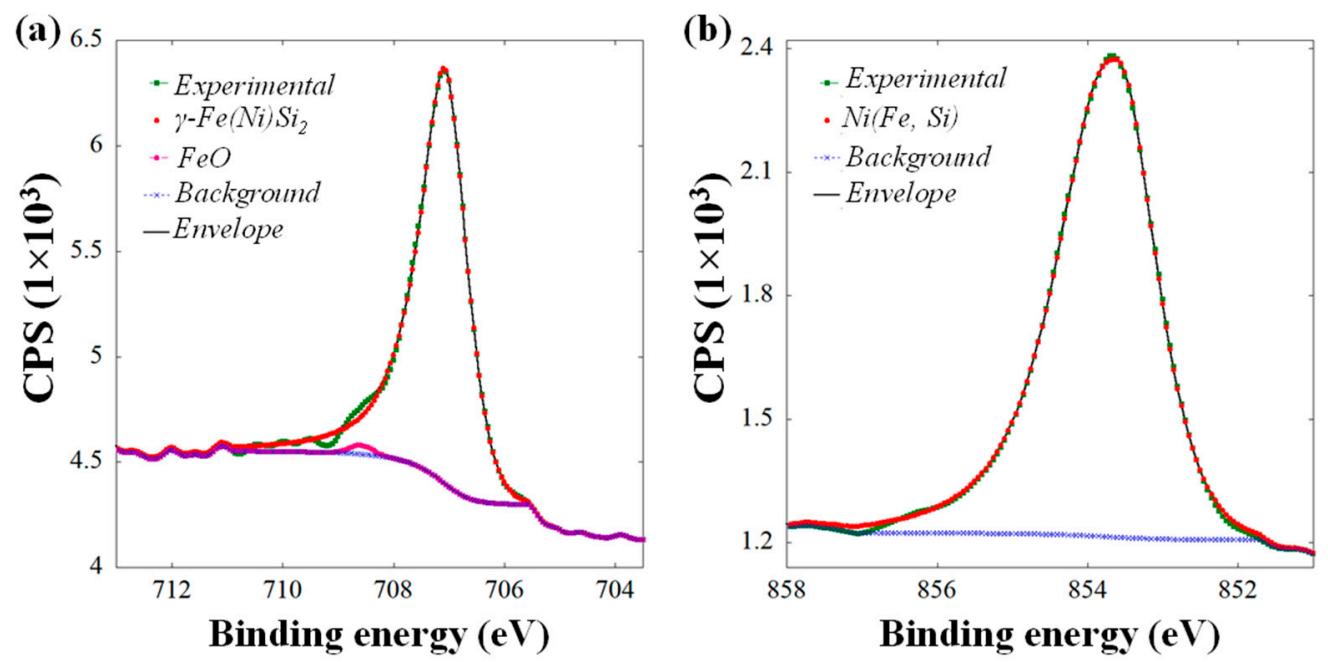

Figure 2. High resolution core level XPS spectra of (a) Fe $2 p_{3 / 2}$ and (b) Ni $2 p_{3 / 2}$ from the selfassembled NSs shown in Figure 1e.

\subsection{Structural and Compositional Analysis}

The structural and compositional analysis of typical $(2 \times 2)$ reconstructed NSs was undertaken by cross-sectional TEM, as shown in Figure 3: HAADF micrograph (3a), and the corresponding Fourier power spectrum (3b), and elemental EDS mapping (3c). Previously, we reported flat-top $\gamma-\mathrm{FeSi}_{2} \mathrm{NSs}$ on $\mathrm{Si}(001)$ [17] or flat-top $\beta$-Fe(Ni)Si ${ }_{2} \mathrm{NSs}$ on $\mathrm{Si}(111)$ [35], that appeared to have only a disk shape in the top view, while in fact having faceted interfaces biting deep into the substrate. However, the pseudomorphic NSs grown in this work exhibited a genuinely disk-like shape, with flat top and bottom facets parallel to the $\mathrm{Si}(111)$ substrate surface, and atomically sharp, plane, and fully coherent interface (Figure 3a). Further, although caution must be exercised when defining the crystal structure 
of a 3-4 atomic layer thick NS, the real and Fourier space analysis of the NSs points to a $\mathrm{CaF}_{2}$-type crystal structure consistent with the $\gamma-\mathrm{FeSi}_{2}$ phase viewed along [112] zone axis, corroborated the conclusion of the XPS analysis above. The interplanar spacings of the $\mathrm{Si}$ substrate were marked as " $\mathrm{d}_{\mathrm{hkl}}$ " and of the NS as " $\mathrm{d}_{\text {'hkl }}$ ", with measured $\mathrm{d}_{111}=0.33 \mathrm{~nm}$, $\mathrm{d}_{220}=0.20 \mathrm{~nm}$, and $\mathrm{d}^{\prime}{ }_{111}=0.31 \mathrm{~nm}$ and $\mathrm{d}_{220}^{\prime}=0.20 \mathrm{~nm}$, respectively.

Figure $3 a, b$ indicates the following epitaxial orientation relations with substrate: $\{111\}_{\mathrm{Si}}$ $\|\{111\}_{\gamma}$ and $\{110\}_{\text {Si }} \|\{110\}_{\gamma}$. The EDS compositional mapping analysis revealed a uniform distribution of $\mathrm{Fe}, \mathrm{Ni}$ and $\mathrm{Si}$ within the entire region of the NS (Figure 3c), signalling the formation of a truly ternary $\gamma-\left(\mathrm{Fe}_{\mathrm{x}} \mathrm{Ni}_{1-\mathrm{x}}\right) \mathrm{Si}_{2}$. We conclude that limiting the annealing temperature to $550{ }^{\circ} \mathrm{C}$ achieved the stated two-fold goal of staying below the temperature where (a) Ni in-diffusion and segregation towards the NS/Si interface practically renders the major top part of the $\beta$-NS devoid of $\mathrm{Ni}$ (as shown in Figure $3 \mathrm{~d}$, for comparison), and (b) $\gamma \rightarrow \beta$ transformation takes place [35].

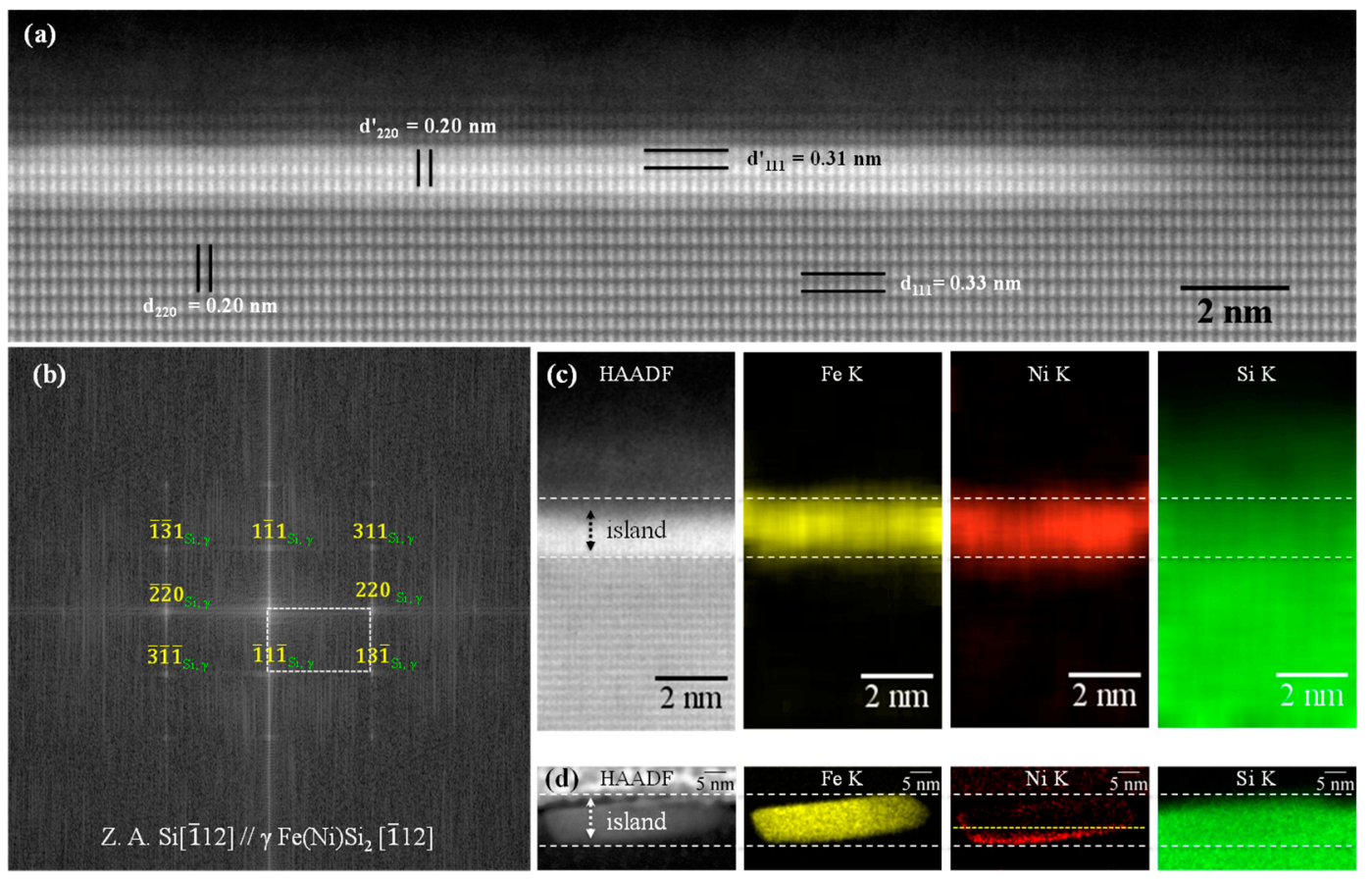

Figure 3. STEM analysis of typical $\gamma-\left(\mathrm{Fe}_{x} \mathrm{Ni}_{1-\mathrm{x}}\right) \mathrm{Si}_{2} \mathrm{NSs}$ : (a) cross-sectional HAADF micrograph, (b) corresponding Fourier power spectrum demonstrating $[\overline{1} 12]_{\mathrm{Si}}||[\overline{1} 12]_{\gamma}$ zone axis, and (c) HAADF and Fe-K, Ni-K, Si-K EDS maps. White broken lines in (c) outline the top and bottom $\gamma-\left(\mathrm{Fe}_{\mathrm{x}} \mathrm{Ni}_{1-\mathrm{x}}\right) \mathrm{Si}_{2} \mathrm{NS}$ boundaries. (d) HAADF STEM micrograph and corresponding EDS elemental mapping of a representative $\beta-\mathrm{Fe}(\mathrm{Ni}) \mathrm{Si}_{2}$ phase NS given here for comparison, where white broken lines outline the top and bottom NS boundaries, and a yellow broken line roughly indicates the top boundary of the Ni-containing region close to the $\beta-\mathrm{Fe}(\mathrm{Ni}) \mathrm{Si}_{2} / \mathrm{Si}(111)$ interface.

\subsection{Magnetometry}

To elucidate the magnetic properties of the self-assembled $\gamma-\left(\mathrm{Fe}_{x} \mathrm{Ni}_{1-\mathrm{x}}\right) \mathrm{Si}_{2}$ NSs shown in Figure 1e,f, we acquired in-plane temperature-dependent magnetization reversal loops, and zero field cooled (ZFC) and field cooled (FC) curves. The systematic increase of the coercive field, saturation magnetic moment, and hysteresis loop area upon the measurement temperature lowering are apparent in Figure $4 \mathrm{a}-\mathrm{c}$. For example, the coercive field $\mathrm{H}_{\mathrm{c}} \sim 72.4$ Oe recorded at $\mathrm{RT}$, increased to $\mathrm{H}_{\mathrm{c}} \sim 104.2$ Oe at $150 \mathrm{~K}$, and to $\mathrm{H}_{\mathrm{c}} \sim 166.0$ Oe at $4 \mathrm{~K}$ (Figure $4 \mathrm{a}-\mathrm{c})$. The $\mathrm{ZFC} / \mathrm{FC}$ curves indicate the bifurcation point temperature $\left(\mathrm{T}_{\text {irr }}\right)$ in the vicinity of RT and a blocking temperature $T_{b}$ at $\sim 30 \mathrm{~K}$ (Figure 5), consistent with SPM behavior, where, however, transition to the blocked state for the largest NSs in the assembly takes place already at RT. The onset of transition to the blocked state for the NS distribution mean size was signified by $\mathrm{T}_{\mathrm{b}}$. Such classical SPM behavior of noninteracting 
NSs is quite different from that in the presence of dipolar (namely SFM or SSG [17,19]) or direct exchange (e.g., ESM) interactions [35]. The magnetization reversal curve of the latter ESM was plotted up to scale, together with the present SPM one in Figure 4d for comparison (both measured at $150 \mathrm{~K}$ ). Significant differences in the shape and opening of the hysteresis loop, as well as in the value of saturation magnetic moment, are apparent, most notably in the vicinity of the inflection points towards saturation magnetization. Absence of a clear bifurcation $T_{\text {irr }}$ point, and a large temperature gap between the $T_{\text {irr }}$ and $\mathrm{T}_{\mathrm{b}}$, reflect the broad size and shape anisotropy distribution of the NSs in the assembly (cf. Figure $1 \mathrm{c}, \mathrm{e})$, and possibly the presence of two different $(2 \times 2)$ and $(\sqrt{3} \times \sqrt{3}) \mathrm{R} 30^{\circ} \mathrm{NS}$ populations.
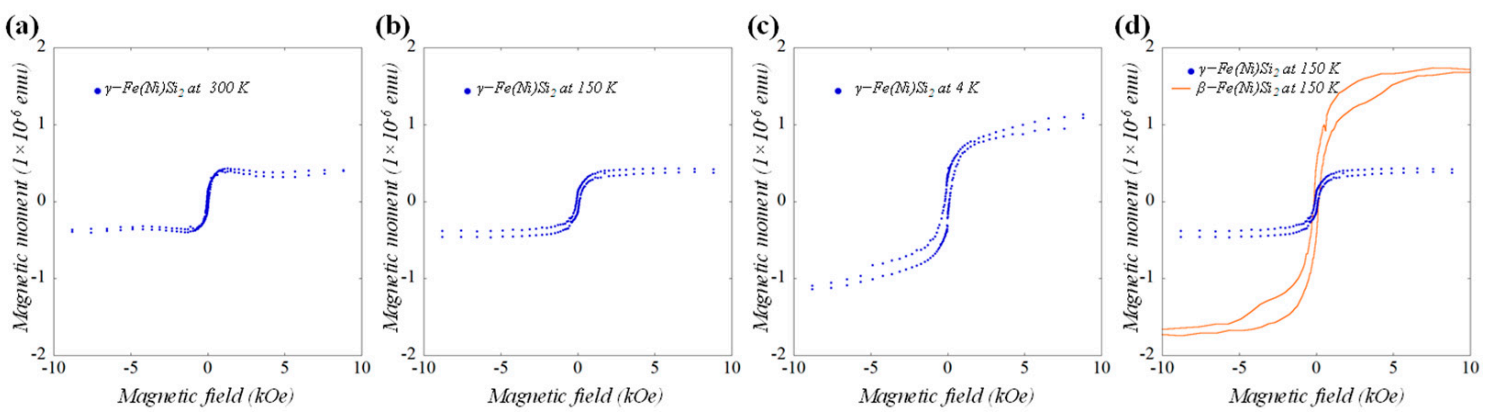

Figure 4. In-plane magnetization reversal loop of grown assembly of $\gamma$-Fe(Ni)Si ${ }_{2}$ NSs measured at (a) $300 \mathrm{~K}$, (b) $150 \mathrm{~K}$ and (c) $4 \mathrm{~K}$. Observed loop at $150 \mathrm{~K}$ for $\gamma$ phase is compared with $\beta$ phase in (d). The displayed magnetic moments have been normalized to reflect the twice larger volume of the as-deposited Py film in the $\gamma$-sample in comparison with that used to produce the $\beta$-sample in (d).

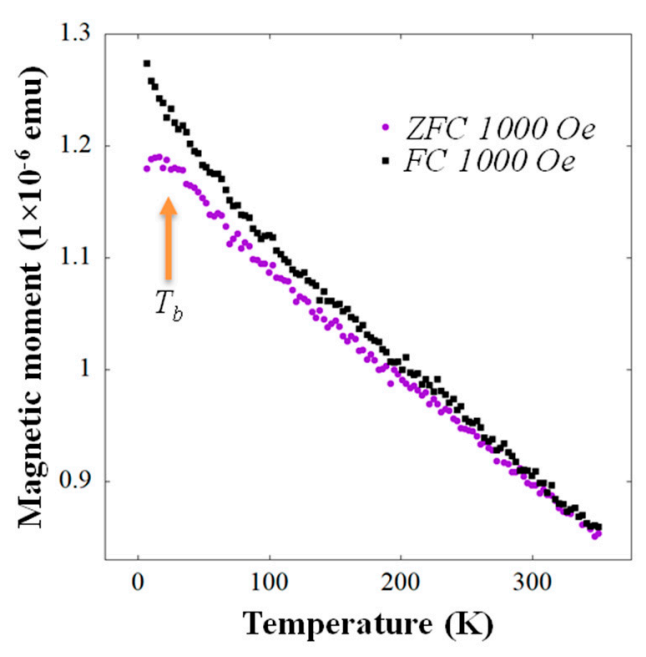

Figure 5. Temperature dependent, in-plane ZFC/FC study for assembly of the $\gamma$ phase NSs with application of external magnetic field 1000 Oe.

\section{Conclusions}

The metastable $\mathrm{CaF}_{2}$-type $\gamma-\mathrm{FeSi}_{2}$ structure often precedes the thermodynamically stable $\alpha-\mathrm{FeSi}_{2}$ and $\beta-\mathrm{FeSi}_{2}$ phases in thin epitaxial deposits. The purpose of this work was to exercise control over the sequence of phase formation and transformations in epitaxial silicide islands, with the aim of controlling the resulting physical properties of the soformed nanosilicide arrays. In particular, we were interested in the magnetic properties of the reaction products of a soft Fe-Ni alloy $\left(\mathrm{Ni}_{80} \mathrm{Fe}_{20} \mathrm{Py}\right.$, in this case) with $\mathrm{Si}$, for a potential use in Si-based memory circuits and spintronic technology. Our previous experiments indicated that the ternary $\mathrm{Fe}-\mathrm{Ni}$-Si silicide phase transformation sequence followed the anticipated $\gamma \rightarrow \beta$ pattern, with, however, one significant difference-massive in-diffusion 
and segregation of $\mathrm{Ni}$ towards the interface with the Si substrate, resulting in a fascinating phenomenon of compositional separation of otherwise crystallographically identical $\beta$ phase into two magnetically different entities, whose coupling yielded an ESM behavior.

Here, the aim was to form and stabilize ternary $\gamma$-disilicide islands and to avoid the loss of $\mathrm{Ni}$, which was indeed achieved by limiting the maximum annealing temperature to $550{ }^{\circ} \mathrm{C}$. On $\mathrm{Si}(111)$ surface, such a controlled heat treatment resulted in the formation of discrete compact ternary silicide NDs, with flat $(2 \times 2)$ or $(\sqrt{3} \times \sqrt{3}) \mathrm{R} 30^{\circ}$ reconstructed tops and fully coherent, pseudomorphic, and atomically sharp interfaces.

Morphologically, although the islands were quite densely populating the preferential step-edge sites on the vicinal $\mathrm{Si}(111)$ surface, significant elongation into wires or long stripes did not eventually occur, leaving quite large gaps between the islands. Hence magnetically, formation of ESM was prevented by keeping the temperature low, and previously observed phenomena based on inter-island interactions, such as dipolar SSG or SFM, did not take place either. Instead, the SPM characteristic of a dilute ensemble of nanoparticles was apparent, with no clearly defined ZFC/FC bifurcation point and median blocking temperature around $30 \mathrm{~K}$, reflecting the broad size, shape, and top-reconstruction distribution of the ternary $\gamma-\left(\mathrm{Fe}_{x} \mathrm{Ni}_{1-x}\right) \mathrm{Si}_{2}$ nanostructures with a small mean size.

Control over the magnetic behavior of the nanoislands on Si surfaces through meticulous control over structural, morphological and compositional characteristics of their assembly, is imperative for applications in high-density data storage and spintronic devices.

Author Contributions: Investigation, data curation, writing —original draft, visualization, formal analysis, A.B.; investigation, data curation, visualization, formal analysis, resources, D.H.; formal analysis, methodology, validation, writing - review and editing, A.K.; conceptualization, methodology, validation, writing - review and editing, visualization, supervision, project administration, funding acquisition, resources, I.G. All authors have read and agreed to the published version of manuscript.

Funding: Present research work has been supported by Israel Science Foundation (Grants No. 1156/19, 1314/17) and PBC Fellowship Program for Outstanding Chinese and Indian Post-Doctoral Fellows of the Israel Council for Higher Education.

Institutional Review Board Statement: Not applicable.

Informed Consent Statement: Not applicable.

Data Availability Statement: Data is contained within the present article.

Acknowledgments: The authors gratefully acknowledge S. Meir (TAU DMSE), P. Shekhter (TAU WAMRC), L. Burstein (TAU WAMRC), G. Leitus (WIS), G. Levi (TAU DMSE, TAU WAMRC), S. Remennik (HUJI), A. Vakahi (HUJI) for their technical support.

Conflicts of Interest: The authors declare no conflict of interest.

\section{References}

1. Hirohata, A.; Yamada, K.; Nakatani, Y.; Prejbeanu, I.-L.; Diény, B.; Pirro, P.; Hillebrands, B. Review on spintronics: Principles and device applications. J. Magn. Magn. Mater. 2020, 509, 166711. [CrossRef]

2. Lin, X.; Yang, W.; Wang, K.L.; Zhao, W. Two-dimensional spintronics for low-power electronics. Nat. Electron. 2019,2 , $274-283$. [CrossRef]

3. Nandwana, V.; Chaubey, G.S.; Yano, K.; Rong, C.-B.; Liu, J.P. Bimagnetic nanoparticles with enhanced exchange coupling and energy products. J. Appl. Phys. 2009, 105, 014303. [CrossRef]

4. Lee, J.; Kim, J.; Kim, D.; Lee, G.; Oh, Y.-B.; Hwang, T.-Y.; Lim, J.-H.; Cho, H.-B.; Kim, J.; Choa, Y.-H. Exchange-coupling interaction in zero- and one-dimensional $\mathrm{Sm}_{2} \mathrm{Co}_{17} / \mathrm{FeCo}$ core-shell nanomagnets. ACS Appl. Mater. Interfaces 2019, 11, $26222-26227$. [CrossRef]

5. Jiang, J.S.; Pearson, J.E.; Liu, Z.Y.; Kabius, B.; Trasobares, S.; Miller, D.J.; Bader, S.D. Improving exchange-spring nanocomposite permanent magnets. Appl. Phys. Lett. 2004, 85, 5293. [CrossRef]

6. Jiang, J.S.; Pearson, J.E.; Liu, Z.Y.; Kabius, B.; Trasobares, S.; Miller, D.J.; Bader, S.D. A new approach for improving exchangespring magnets. J. Appl. Phys. 2005, 97, 10K311. [CrossRef]

7. Liu, Y.; Wu, Y.Q.; Kramer, M.J.; Choi, Y.; Jiang, J.S.; Wang, Z.L.; Liu, J.P. Microstructure analysis of a SmCo/Fe exchange spring bilayer. Appl. Phys. Lett. 2008, 93, 192502. [CrossRef] 
8. Zeng, H.; Li, J.; Liu, J.P.; Wang, Z.L.; Sun, S. Exchange-coupled nanocomposite magnets by nanoparticle self-assembly. Nature 2002, 420, 395-398. [CrossRef] [PubMed]

9. Hamdeh, H.H.; Eltabey, M.M.; Ho, J.C.; Lee, P.C.; Chen, K.; Chen, Y.Y. Magnetism in nanoparticles of semiconducting FeSi 2. J. Magn. Magn. Mater. 2010, 322, 2227-2230. [CrossRef]

10. Seo, K.; Varadwaj, K.S.K.; Mohanty, P.; Lee, S.; Jo, Y.; Jung, M.-H.; Kim, J.; Kim, B. Magnetic Properties of Single-Crystalline CoSi Nanowires. Nano Lett. 2007, 7, 1240-1245. [CrossRef]

11. Chen, Y.Y.; Lee, P.C.; Tsai, C.B.; Neeleshwar, S.; Wang, C.R.; Ho, J.C.; Hamdeh, H.H. Chemical disorder-induced magnetism in $\mathrm{FeSi}_{2}$ nanoparticles. Appl. Phys. Lett. 2007, 91, 251907. [CrossRef]

12. Shi, H.; Chang, L.; Jia, R.; Eglitis, R.I. Ab initio calculations of the transfer and aggregation of F centers in CaF 2. J. Phys. Chem. C 2012, 116, 4832-4839. [CrossRef]

13. Bedanta, S.; Kleemann, W. Supermagnetism. J. Phys. D Appl. Phys. 2009, 42, 013001. [CrossRef]

14. Coey, J.M.D. Magnetism and Magnetic Materials; Cambridge University Press: New York, NY, USA, 2010.

15. Petracic, O. Superparamagnetic nanoparticle ensembles. Superlattices Microstruct. 2010, 47, 569-578. [CrossRef]

16. Tripathi, J.K.; Levy, R.; Camus, Y.; Dascalu, M.; Cesura, F.; Chalasani, R.; Kohn, A.; Markovich, G.; Goldfarb, I. Self-organized growth and magnetic properties of epitaxial silicide nanoislands. Appl. Surf. Sci. 2017, 391, 24-32. [CrossRef]

17. Goldfarb, I.; Camus, Y.; Dascalu, M.; Cesura, F.; Chalasani, R.; Kohn, A. Tuning magnetic response of epitaxial iron-silicide nanoislands by controlled self-assembled growth. Phys. Rev. B 2017, 96, 045415. [CrossRef]

18. Tripathi, J.K.; Garbrecht, M.; Kaplan, W.D.; Markovich, G.; Goldfarb, I. The effect of Fe-coverage on the structure, morphology and magnetic properties of $\alpha-\mathrm{FeSi}_{2}$ nanoislands. Nanotechnology 2012, 23, 495603. [CrossRef]

19. Dascalu, M.; Cesura, F.; Levi, G.; Diéguez, O.; Kohn, A.; Goldfarb, I. Controlling the supermagnetic response of tetragonal $\alpha$-FeSi 2 nanoislands. Appl. Surf. Sci. 2019, 476, 189-197. [CrossRef]

20. Tripathi, J.K.; Markovich, G.; Goldfarb, I. Self-ordered magnetic $\alpha$-FeSi 2 nano-stripes on Si(111). Appl. Phys. Lett. 2013, 102, 251604. [CrossRef]

21. Goldfarb, I.; Cesura, F.; Dascalu, M. Magnetic Binary Silicide Nanostructures. Adv. Mater. 2018, 30, 1800004. [CrossRef] [PubMed]

22. Goldfarb, I. Step-mediated size selection and ordering of heteroepitaxial nanocrystals. Nanotechnology 2007, 18, 335304. [CrossRef]

23. Tripathi, J.K.; Garbrecht, M.; Sztrum-Vartash, C.G.; Rabani, E.; Kaplan, W.D.; Goldfarb, I. Coverage-dependent self-organized ordering of Co- and Ti-silicide nanoislands along step-bunch edges of vicinal Si(111). Phys. Rev. B 2011, 83, 165409. [CrossRef]

24. Liang, S.; Islam, R.; Smith, D.J.; Bennett, P.A.; O’Brien, J.R.; Taylor, B. Magnetic iron silicide nanowires on Si(110). Appl. Phys. Lett. 2006, 88, 113111. [CrossRef]

25. Massalski, T.B.; Okamoto, H.; Subramanian, P.R.; Kacprzak, L. Binary Alloy Phase Diagrams, 2nd ed.; ASM International: Materials Park, OH, USA, 1990.

26. Leong, D.; Harry, M.; Reeson, K.J.; Homewood, K.P. A silicon/iron-disilicide light-emitting diode operating at a wavelength of $1.5 \mu \mathrm{m}$. Nature 1997, 387, 686-688. [CrossRef]

27. Christensen, N.E. Electronic structure of $\beta-\mathrm{FeSi}_{2}$. Phys. Rev. B 1990, 42, 7148. [CrossRef]

28. Gomoyunova, M.V.; Malygin, D.E.; Pronin, I.I.; Voronchikhin, A.S.; Vyalikh, D.V.; Molodtsov, S.L. Initial stages of iron silicide formation on the Si(100) $2 \times 1$ surface. Surf. Sci. 2007, 601, 5069-5076. [CrossRef]

29. Wallart, X.; Nys, J.P.; Tételin, C. Growth of ultrathin iron silicide films: Observation of the $\gamma$-FeSi 2 phase by electron spectroscopies. Phys. Rev. B 1994, 49, 5714. [CrossRef]

30. Onda, N.; Henz, J.; Müller, E.; Mäder, K.A.; von Känel, H. Epitaxy of fluorite-structure silicides: Metastable cubic FeSi ${ }_{2}$ on Si(111). Appl. Surf. Sci. 1992, 56-58, 421-426. [CrossRef]

31. Von Känel, H.; Onda, N.; Sirringhaus, H.; Muller-Gubler, E.; Goncalves-Conto, S.; Schwarz, C. Epitaxial phase transitions in the iron/silicon system. Appl. Surf. Sci. 1993, 70-71, 559-563. [CrossRef]

32. Alvarez, J.; de Parga, A.L.V.; Hinarejos, J.J.; de la Figuera, J.; Michel, E.G.; Ocal, C.; Miranda, R. Structural phase transition during heteroepitaxial growth of iron silicides on Si(111). Appl. Surf. Sci. 1993, 70-71, 578-582. [CrossRef]

33. Liang, S.; Islam, R.; Smith, D.J.; Bennett, P.A. Phase transformation in FeSi 2 nanowires. J. Cryst. Growth 2006, $295,166-171$. [CrossRef]

34. Geng, L.D.; Dhoka, S.; Goldfarb, I.; Pati, R.; Jin, Y.M. Origin of magnetism in $\gamma-\mathrm{FeSi}_{2} / \mathrm{Si}(111)$ nanostructures. Nanomaterials 2021, 11, 849. [CrossRef]

35. Bhukta, A.; Levi, G.; Horvitz, D.; Kohn, A.; Goldfarb, I. Self-organized exchange-spring magnet in epitaxial $\beta$-Fe(Ni)Si $2 / S i$ system. Appl. Surf. Sci. in press.

36. Casa XPS; Casa Software: Wilmslow, UK, 2001. Available online: http:/ /www.casaxps.com/ (accessed on 31 January 2021).

37. Shirley, D.A. High-resolution X-ray photoemission spectrum of the valence bands of gold. Phys. Rev. B 1972, 5, 4709. [CrossRef]

38. Dascalu, M.; Diéguez, O.; Geng, L.D.; Pati, R.; Jin, Y.M.; Goldfarb, I. Tomographic layer-by-layer analysis of epitaxial iron-silicide nanostructures by DFT-assisted STS. Appl. Surf. Sci. 2019, 496, 143583. [CrossRef]

39. Nagai, Y.; Senda, M.; Toshima, T. XPS investigations of Ni-Fe alloy and Fe films. Jpn. J. Appl. Phys. 1987, 6, 1131. [CrossRef]

40. Asami, K.; Hashimoto, K.; Shimodaira, S. X-ray photoelectron spectrum of $\mathrm{Fe}^{2+}$ state in iron oxides. Corros. Sci. 1976, 16, 35-45. [CrossRef]

41. Marchetti, L.; Miserque, F.; Perrin, S.; Pijolat, M. XPS study of Ni-base alloys oxide films formed in primary conditions of pressurized water reactor. Surf. Interface Anal. 2015, 47, 632-642. [CrossRef] 
42. Nesbitt, H.W.; Legrand, D.; Bancroft, G.M. Interpretation of Ni2p XPS spectra of Ni conductors and Ni insulators. Phys. Chem. Miner. 2000, 27, 357-366. [CrossRef]

43. Grosvenor, A.P.; Biesinger, M.C.; Smart, R.S.C.; McIntyre, N.S. New interpretations of XPS spectra of nickel metal and oxides. Surf. Sci. 2006, 600, 1771-1779. [CrossRef]

44. Yu, G.H.; Zhao, H.C.; Li, M.H.; Zhu, F.W.; Lai, W.Y. Interface reaction of Ta $/ \mathrm{Ni}_{81} \mathrm{Fe}_{19}$ or $\mathrm{Ni}_{81} \mathrm{Fe}_{19} / \mathrm{Ta}$ and its suppression. Appl. Phys. Lett. 2002, 80, 455-457. [CrossRef]

45. Khan, W.; Wang, Q.; Jin, X. Effect of target composition and sputtering deposition parameters on the functional properties of nitrogenized Ag-Permalloy flexible thin films deposited on polymer substrates. Materials 2018, 11, 439. [CrossRef] [PubMed]

46. Tam, P.L.; Nyborg, L. Sputter deposition and XPS analysis of nickel silicide thin films. Surf. Coat. Technol. 2009, 203, 2886-2890. [CrossRef]

47. Salou, M.; Lescop, B.; Rioual, S.; Lebon, A.; Youssef, J.B.; Rouvellou, B. Initial oxidation of polycrystalline Permalloy surface. Surf. Sci. 2008, 602, 2901-2906. [CrossRef] 